\title{
Magnetic Resonance Imaging and Cone Beam CT Image Registration for Osseous and Soft Tissue Abnormalities of Temporomandibular Joint: A Systematic Review
}

\author{
Ravleen Nagi ${ }^{1}$ Rakesh Nagaraju ${ }^{2}$ Giridhar S. Naidu ${ }^{3}$ \\ Ramanpal Singh Makkad ${ }^{3}$ \\ ${ }^{1}$ Department of Oral Medicine and Radiology, Swami Devi Dyal \\ Dental College, Panchkula, Haryana, India \\ 2Department of Oral Medicine and Radiology, Faculty of Dental \\ Sciences, M.S. Ramaiah University of Applied Sciences, Bangalore, \\ Karnataka, India \\ ${ }^{3}$ Department of Oral Medicine and Radiology, New Horizon Dental \\ College and Research Institute, Bilaspur, Chhattisgarh, India \\ ${ }^{4}$ Department of Oral Medicine and Radiology, Government Dental \\ College, Indore, Madhya Pradesh, India \\ ${ }^{5}$ Department of Oral and Maxillofacial Surgery, Genesis Institute of \\ Dental Sciences and Research, Ferozepur, Punjab, India
}

Prashanthi Reddy ${ }^{4}$ Ajay Bibra ${ }^{5}$

\author{
Address for correspondence Ravleen Nagi, BDS, MDS, \\ Department of Oral Medicine and Radiology, Swami Devi Dyal \\ Hospital and Dental College, Panchkula, Haryana 140603, India \\ (e-mail: ravleennagi@yahoo.in).
}

\section{Abstract}

Keywords

- articular disc

- accuracy

- registration

- magnetic resonance imaging

- cone beam computed tomography
Introduction Proper diagnosis of temporomandibular disorders (TMDs) is paramount for proper management. Cone beam computed tomography (CBCT) provides additional information about osseous components of TMJ, but diagnosis of soft tissue abnormalities is still a challenging issue for the clinicians. To overcome this, magnetic resonance imaging (MRI) and $\mathrm{CBCT}$ registration has shown to be a new promising technique that combines key features of both images into one single fusion image. The purpose of this systematic review was to compile available literature regarding the usefulness of $\mathrm{CBCT}$ and MRI-CBCT fusion imaging in proper diagnosis of temporomandibular joint (TMJ) abnormalities.

Materials and Methods Computerized literature search from January 2010 to 2020 using five databases: PubMed (MEDLINE) database (National Library of Medicine, NCBI), Cochrane Database, Scopus, Embase, and Science Direct was conducted by use of medical specific headings (MeSH) keywords.

Results Only 10 articles met the inclusion criteria. Eight articles showed that CBCT accurately detected osseous components of TMJ but has low reliability in diagnosing soft tissue articular disc disorders. Relationship between hard and soft tissues were clearly visualized in fused images.

Conclusion MRI-CBCT image registration is a reliable diagnostic tool for simultaneous evaluation of osseous and soft tissue abnormalities of TMJ and in future more studies should be encouraged to validate its accuracy for TMJ analysis.
DOI https://doi.org/

$10.1055 / \mathrm{s}-0041-1723876$ ISSN 2321-1482.
(C2021. Bhojia Dental College and Hospital affiliated to Himachal Pradesh University.

This is an open access article published by Thieme under the terms of the Creative Commons Attribution-NonDerivative-NonCommercial-License, permitting copying and reproduction so long as the original work is given appropriate credit. Contents may not be used for commercial purposes, or adapted, remixed, transformed or built upon. (https://creativecommons.org/licenses/by-nc-nd/4.0/) Thieme Medical and Scientific Publishers Pvt. Ltd. A-12, 2nd Floor Sector 2, Noida-201301 UP, India 


\section{Introduction}

Dental professionals encounter various maxillofacial pathologies such as temporomandibular disorders (TMDs), chronic orofacial pain, neuropathic pain conditions, etc. with overlapping and unexplained symptoms, and these become a diagnostic challenge for a practitioner. In these situations, imaging plays a crucial role in arriving at accurate diagnosis and proper treatment plan toward better treatment outcome. ${ }^{1}$ Nowadays, three-dimensional (3D) imaging modalities such as cone beam computed tomography (CBCT) are becoming popular due to their potential advantages of high spatial resolution in comparison to 2D panoramic radiography and lower radiation dose and cost than medical computed tomography. Moreover, they provide multiplanar reconstructed images of the region of interest and have overcome the limitations of magnification, distortion, and superimposition of anatomical structures that usually occur in panoramic images. ${ }^{1,2}$ CBCT images could be optimized for better visualization of anatomical structures and region of interest.

CBCT provides 3D volumetric images of the dental arches and the surrounding tissue and is presently being used in various dental disciplines such as in cephalometric evaluation, dental implantology, image guided surgery, maxillofacial trauma, airway analysis, and in diagnosis of TMDs. ${ }^{3-6}$ TMDs are heterogeneous group of complex disorders that affect the masticatory musculature, TMJ, and tendon. Clinical symptoms of pain, click, otalgia, limitation in mouth opening, and deviation of jaw are seen commonly affecting 28 to $86 \%$ of adults and adolescents. ${ }^{7}$ American Academy of Orofacial Pain has diagnostically classified TMDs as masticatory muscle and articular disorders. Although patient's history and clinical examination play a primarily role in diagnosis, they could not rule out the exact etiopathogenesis of TMDs in some patients and this necessitates further diagnostic confirmation by 3D imaging modalities. ${ }^{7}$ Magnetic resonance imaging (MRI) has been proven to provide clear visualization of disc position and morphology, condylar translation, synovitis, joint effusions, and to lesser extent osseous changes. CT has been considered best for viewing bony changes, but main concern is radiation exposure. Recently, СBCT has shown high diagnostic value in analysis of TMJ osseous abnormalities; degenerative joint disorders; condylar changes such as erosions, fractures, and osteophytes; and TMJ ankylosis. Clear visualization of articular disc position and abnormalities on CBCT images is still questionable; therefore, MRI-CBCT registration is new to dentistry that combines characteristics of both images and results in single fused image to improve diagnosis and interpretation of TMJ disorders. ${ }^{8,9}$

Even though studies have shown that CBCT doses (30-80 $\mu \mathrm{Sv}$ for restricted anatomical volumes in the maxillofacial region) are less than medical CT, but when compared with conventional imaging procedures (intraoral and panoramic), effectives doses are higher. ${ }^{10,11}$ In addition, old CBCT scanners with large field of view (FOV) results in higher radiation doses while imaging TMJ anatomical structures. To overcome this, old CBCT scanners have been optimized by alteration of FOV, angle of rotation, collimation, pulsed exposure, etc. that reduces radiation dose. In 2014, new concept emerged in which there was shift from "as low as reasonably achievable" (ALARA) to "as low as diagnostically acceptable (ALADA)" which states that CBCT should be considered as an adjunctive diagnostic tool to standard imaging modalities, and patients should be indicated for CBCT examination if the disease or condition could not be diagnosed accurately by 2D radiography and further 3D analysis is required for formulating proper treatment plan. ${ }^{12}$ The aim of this review was to summarize evidence-based clinical studies from preexisting literature regarding usefulness of dental CBCT and MRI-CBCT fused images in the analysis of both osseous and soft tissue abnormalities of TMJ. It also discusses low-dose protocols that have optimized the old CBCT scanners to perform examination at a relatively reduced radiation dose.

\section{Materials and Methods}

\section{Aim and Objective}

The aim of this article was to summarize the data from available literature related to diagnostic performance of $\mathrm{CBCT}$ and MRI-CBCT registration for diagnosis and treatment planning of TMDs. Therefore, population intervention comparator outcomes (PICO) approach was formulated as follows: population, TMD patients; intervention, CBCT alone or CBCT-MRI; control/comparison, conventional 2D radiography; and outcome, treatment outcomes due to $3 \mathrm{D}$ CBCT and CBCT-MRI fusion imaging.

\section{Literature Search Methods, Strategy, and Selection Criteria}

The electronic databases searched for the relevant articles were PubMed [MEDLINE] database (National Library of Medicine, NCBI), Cochrane Database, Scopus, Embase, and Science Direct. The search was performed from January 2010 to January 2020 and following medical subject headings (MeSH) were applied during the literature search: articular disc, cone-beam CT, magnetic resonance imaging, registration, fusion, and temporomandibular joint. The PubMed search yielded 107 articles, Science Direct yielded 224 articles, and Cochrane Database, Scopus and Embase yielded 94 articles.

Two reviewers searched the full title and abstract of the articles, and the eligibility criteria was based on PICO method, that is, population, intervention, comparison, and outcome. The articles that were not fulfilling the eligibility criteria, and duplicate articles were not taken into account; differences among the reviewers for the eligible studies were resolved by mutual agreement. Inclusion criteria were all articles published in English in the scientific literature, publications reporting primary studies related to diagnostic efficacy of CBCT alone and CBCT-MRI fusion images in detection of TMJ abnormalities. Articles not meeting the inclusion criteria were excluded. Case reports, narrative, historical reviews, and articles in other languages were excluded. 


\section{Data Extraction}

The following data were extracted and analyzed descriptively from the selected articles on application of dental CBCT alone and MRI-CBCT fusion imaging for TMJ examination: year of publication; population: TMJ patient, intervention; comparison: 2D radiography, effective dose, and author's conclusion or treatment outcome. One reviewer extracted the relevant information from the included articles and the second re-evaluated it. Any disagreement was sorted out by discussion between the reviewers.

\section{Results}

-Fig. 1 shows number of publications identified excluded and included. From the initial search strategy, the PubMed Search yielded 107 articles, Science Direct yielded 224 articles and Cochrane Database, Scopus, and Embase yielded 97 articles. In the first phase of selection, 114 were discarded after reviewing the abstracts, as these publications did not meet the inclusion criteria. The full text of remaining 66 publications was examined, and 10 satisfied the inclusion criteria.
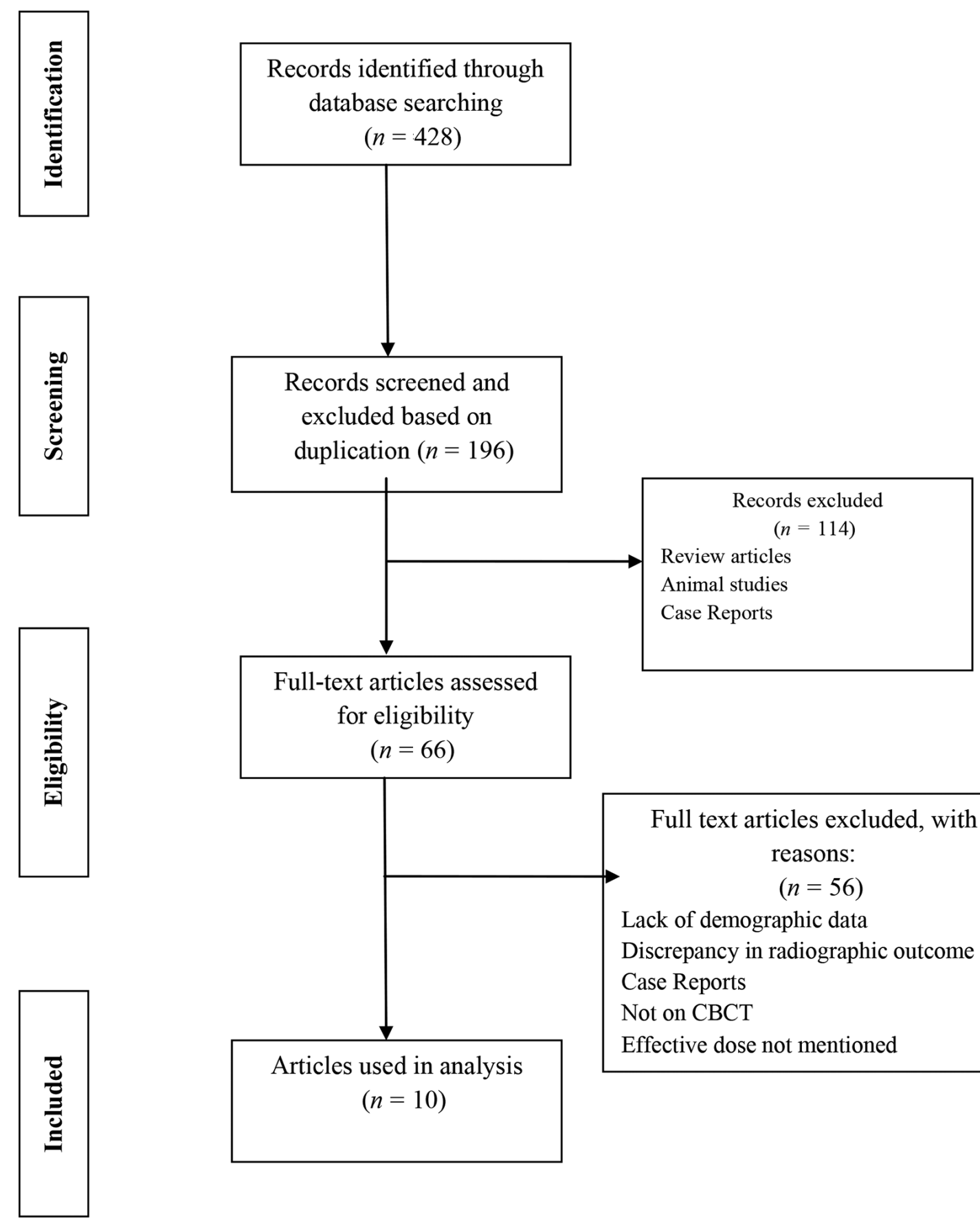

Full-text articles assessed for eligibility $(n=66)$

Full text articles excluded, with reasons: $(n=56)$

Lack of demographic data

Discrepancy in radiographic outcome

Case Reports

Not on CBCT

Effective dose not mentioned

Fig. 1 Preferred reporting items for systematic review diagram showing article selection for diagnostic accuracy of CBCT and magnetic resonance imaging-СBCT fusion imaging in depiction of temporomandibular joint soft tissue and osseous abnormalities. CBCT, cone beam computed tomography. 


\section{Risk of Bias Assessment}

Cochrane Bias Tool revealed low-risk bias in all the selected studies (- Table 1).

- Tables 2 and $\mathbf{3}$ present PICO model of clinical studies conducted to evaluate the accuracy of CBCT alone and MRI-CBCT fused images, respectively, in the detection of TMJ soft tissue and bony abnormalities. ${ }^{8,13-21}$ All the studies showed that $\mathrm{CBCT}$ accurately detected osseous abnormalities of TMJ such as condylar erosion, osteophyte formation, flattening, subchondral cysts, etc. Al-Ekrish et al found low diagnostic accuracy of CBCT in the detection of soft tissue calcifications and 94\% cases showed disagreement between the observers, whereas high diagnostic value was observed for $\mathrm{CBCT}$ in the demonstration of osseous morphology of TMJ. ${ }^{15}$ Yasa and Akgül found significant differences in the anterior joint space, posterior joint space, eminence inclination eminence height, condyle, and fossa shape $(p<0.001)$ between TMD and asymptomatic patients. ${ }^{18}$

Diagnosis of soft tissue abnormalities, that is, articular disc position and morphology, condylar/disc translation, and joint effusions are less demonstrated on CBCT images. Alkhader et al concluded that disc disorders are best visualized on MRI with specificity of 84 to $98 \%$, but it becomes difficult to interpret relationship between the articular disc and mandibular condyle or glenoid fossa on MRI images. ${ }^{8}$ Nowadays, MRI-CBCT registration is becoming popular as it displays characteristic features of hard and soft tissues in one picture frame for optimal diagnosis and treatment plan. Very limited studies have been documented in the literature regarding fusion imaging, and by our search, we found only two studies which stated that relationship between soft mass and hard tissues were clearly seen in the fused images; these could define the destructive bone changes or condylar erosions clearly in the same image. ${ }^{19,21}$ Besides MRI-CBCT fusion imaging, registration of two CBCT images is also a new reliable diagnostic tool for TMJ assessment. Zhou et al in their study found that mean square error of condyle and skull 3D registration declined by 51.80 and $64.58 \%$ than preregistration. ${ }^{19}$

Our literature search analysis suggested that although MRI-CBCT registration is a promising technique for TMJ examination, there are very limited studies on its clinical applications, and future demands more research work on the clinical utility of MRI-CBCT registration for the TMJ assessment.

\section{Discussion}

Temporomandibular disorders encompass clinical problems that originate from TMJ, region, masticatory muscles, and surrounding tissues. The etiology of TMD is multifactorial and is still not clear, but trauma, parafunctional habits, occlusal discrepancies, sleep disorders, craniocervical posture, underlying systemic disease, and psychological stress are considered to be major predisposing factors. ${ }^{8}$ Among them, occlusal interferences and parafunctional habits are common causes responsible for TMDs according to the existing literature, these changes could lead to variable clinical manifestations ranging from preauricular pain, clicking, or crepitation noises; limited mouth opening with deviation of jaw; otalgia, headache; and neck pain. Persistent chronic TMD pain affects daily functional activities of the patient, and in the majority of cases, it is the common cause to seek consultation from the

Table 1 Risk of bias across individual studies

\begin{tabular}{|l|l|l|l|l|l|l|}
\hline Study (Year) & $\begin{array}{l}\text { Randomization } \\
\text { sequence }\end{array}$ & $\begin{array}{l}\text { Allocation } \\
\text { concealment }\end{array}$ & $\begin{array}{l}\text { Blinding of } \\
\text { participants }\end{array}$ & $\begin{array}{l}\text { Blinding of } \\
\text { patient } \\
\text { reported } \\
\text { outcome }\end{array}$ & $\begin{array}{l}\text { Blinding of } \\
\text { outcome } \\
\text { assessment }\end{array}$ & $\begin{array}{l}\text { Incomplete } \\
\text { outcome data }\end{array}$ \\
\hline $\begin{array}{l}\text { Alkhader et al } \\
(2010)^{8}\end{array}$ & - & - & - & - & - & - \\
\hline Nah $(2012)^{13}$ & - & - & - & - & - & - \\
\hline $\begin{array}{l}\text { Wang et al } \\
(2013)^{14}\end{array}$ & + & + & + & + & + & - \\
\hline $\begin{array}{l}\text { Al-Ekrish } \\
(2013)^{15}\end{array}$ & - & - & - & - & - & - \\
\hline $\begin{array}{l}\text { Al-Saleh et al } \\
(2015)^{16}\end{array}$ & - & - & + & + & + & - \\
\hline $\begin{array}{l}\text { Rehan et al } \\
(2018)^{17}\end{array}$ & - & - & - & - & - & - \\
\hline $\begin{array}{l}\text { Yasa and Akgül } \\
(2018)^{18}\end{array}$ & - & - & - & - & - & - \\
\hline $\begin{array}{l}\text { Zhou et al } \\
(2018)^{19}\end{array}$ & - & - & - & - & - & - \\
\hline $\begin{array}{l}\text { Maleki et al } \\
(2018)^{20}\end{array}$ & - & - & - & - & - & - \\
\hline $\begin{array}{l}\text { Ma et al } \\
(2019)^{21}\end{array}$ & - & - & + & + & + & - \\
\hline
\end{tabular}

Note: (+), high risk; (_), low risk. 
Table 2 Population, intervention, comparison, and outcome model summarizes literature studies to evaluate the diagnostic accuracy of cone Beam CT for the diagnosis and management of soft tissue and osseous abnormalities of temporomandibular joint

\begin{tabular}{|c|c|c|c|c|}
\hline $\begin{array}{l}\text { Study } \\
\text { (Year) }\end{array}$ & Population & Intervention & $\begin{array}{l}\text { Comparison/ } \\
\text { Control }\end{array}$ & Outcome \\
\hline $\begin{array}{l}\text { Alkhader et al } \\
(2010)^{8}\end{array}$ & $\begin{array}{l}106 \text { TMJs of } 55 \\
\text { patients with } \\
\text { TMD }\end{array}$ & $\begin{array}{l}\text { Determination of the } \\
\text { diagnostic accuracy } \\
\text { of MRI for assessing } \\
\text { osseous abnormal- } \\
\text { ities of the TMJ and } \\
\text { correlation with } \\
\text { CBCT }\end{array}$ & $\begin{array}{l}\text { 3DX multi-im- } \\
\text { age micro-CT, } \\
\text { CBCT vs. MRI }\end{array}$ & $\begin{array}{l}\text { High specificity ( } 84-98 \% \text { ) was obtained with MRI, this } \\
\text { modality showed relatively low sensitivity (30-82\%) for } \\
\text { detecting osseous abnormalities of the TM] in } \\
\text { comparison to CBCT. }\end{array}$ \\
\hline $\begin{array}{l}\text { Nah } \\
(2012)^{13}\end{array}$ & $\begin{array}{l}440 \text { TMJ of } 220 \\
\text { TMD patients }\end{array}$ & $\begin{array}{l}\text { Evaluation of } \\
\text { condylar changes } \\
\text { in TMD patients by } \\
\text { CBCT(Pax-Zenith 3D) }\end{array}$ & NC & $\begin{array}{l}\text { Most frequent condylar bony changes observed was } \\
\text { sclerosis ( } 133 \text { joints, } 30.2 \%) \text { followed by surface } \\
\text { erosion ( } 129 \text { joints, } 29.3 \%) \text {, flattening of the articular } \\
\text { surface }(112 \text { joints, } 25.5 \%) \text {, and deviation in form } \\
\text { (58 joints, } 13.2 \% \text { ) by CBCT. }\end{array}$ \\
\hline $\begin{array}{l}\text { Wang et al } \\
(2013)^{14}\end{array}$ & $\begin{array}{l}157 \text { patients } \\
\text { with TMDs } \\
41 \text { subjects as } \\
\text { controls }\end{array}$ & $\begin{array}{l}\text { To investigate the } \\
\text { occurrence and } \\
\text { radiographic signs } \\
\text { of osteoarthrosis of } \\
\text { TMJ (TMJOA) with } \\
\text { CBCT in adolescents }\end{array}$ & NC & $\begin{array}{l}\text { CBCT examination showed that occurrence of OA was } \\
\text { significantly higher in the patients group }(40.7 \%, 157 / 386) \\
\text { than in the controls }(12.1 \%, 41 / 339),(p<0.05) . \text { CBCT } \\
\text { imaging depicted more erosive changes in TMD patients. }\end{array}$ \\
\hline $\begin{array}{l}\text { Al-Ekrish } \\
(2013)^{15}\end{array}$ & 491 TMJ & $\begin{array}{l}\text { Reliability of diag- } \\
\text { nosis of soft tissue } \\
\text { calcification of the } \\
\text { TMJ on CBCT (Iluma, } \\
\text { Imtek) images of } \\
\text { TMJ and non-TMJ } \\
\text { patients }\end{array}$ & NC & $\begin{array}{l}\text { The first and second examinations yielded a diagnosis of } \\
\text { calcification present in } 12 \% \text { and } 34 \% \text { of cases, respectively. } \\
\text { In total, } 94 \% \text { cases showed disagreement (low reliability). } \\
\text { Studies are needed to develop CBCT protocols which may } \\
\text { accurately and reliably demonstrate such calcifications. }\end{array}$ \\
\hline $\begin{array}{l}\text { Rehan et al } \\
(2018)^{17}\end{array}$ & $\begin{array}{l}14 \text { RA patients } \\
14 \text { normal } \\
\text { subjects }\end{array}$ & $\begin{array}{l}\text { To evaluate osseous } \\
\text { changes of TMJ in } \\
\text { patients with RA } \\
\text { using CBCT }\end{array}$ & NC & $\begin{array}{l}\text { CBCT accurately detected higher prevalence of erosion } \\
\text { ( } 85.7 \%) \text {, flattening }(89.3 \%) \text {, osteophyte formation ( } 32.1 \%) \text {, } \\
\text { subchondral cyst (32.1\%), sclerosis (64.3\%), and condylar } \\
\text { irregularities ( } 28.6 \%) \text { in the RA patients than the controls. }\end{array}$ \\
\hline $\begin{array}{l}\text { Yasa et al } \\
(2018)^{18}\end{array}$ & $\begin{array}{l}200 \text { TMD } \\
\text { patients } \\
200 \text { asympto- } \\
\text { matic patients }\end{array}$ & $\begin{array}{l}\text { Evaluation of TMJ } \\
\text { osseous morphology }\end{array}$ & NC & $\begin{array}{l}\text { Significant differences in the anterior joint space } \\
(p<0.0001) \text {, ratio of anterior joint space to posterior joint } \\
\text { space }(p<0.001) \text {, posterior joint space }(p<0.05) \text {, eminence } \\
\text { inclination }(p<0.05) \text {, eminence height }(p<0.05) \text {, condyle } \\
\text { shape }(p<0.0001) \text {, and fossa shape }(p<0.05) \text { was seen } \\
\text { between the groups. } \\
\text { Steeper articular eminence inclination may be risk factor } \\
\text { for TMD. }\end{array}$ \\
\hline $\begin{array}{l}\text { Zhou et al } \\
(2018)^{19}\end{array}$ & $\begin{array}{l}10 \mathrm{TMJ} \\
\text { samples of } 6 \\
\text { patients } \\
\text { Bilateral TMJ: } 4 \\
\text { patients } \\
\text { Unilateral: } 2 \\
\text { patients }\end{array}$ & $\begin{array}{l}\text { Quantitative and } \\
\text { qualitative analysis } \\
\text { of TMJ bone changes } \\
\text { by 2D and 3D } \\
\text { registration }\end{array}$ & $\begin{array}{l}\text { 2D color fused } \\
\text { Model }\end{array}$ & $\begin{array}{l}\text { Osseous and morphological changes were well displayed } \\
\text { using fusion imaging. Mean square error of condyle and skull } \\
\text { registration declined by } 51.80 \text { and } 64.58 \% \text { preregistration. }\end{array}$ \\
\hline $\begin{array}{l}\text { Maleki et al } \\
(2018)^{20}\end{array}$ & $\begin{array}{l}160 \mathrm{TMJ} \text { of } 80 \\
\text { patients }\end{array}$ & $\begin{array}{l}\text { To investigate the } \\
\text { bone changes in the } \\
\text { patients with TMD } \\
\text { symptoms using } \\
\text { CBCT (PLANMECA, } \\
\text { Finland) }\end{array}$ & $\mathrm{NC}$ & $\begin{array}{l}132 \text { cases of flattening ( } 82.5 \%) \text {, of sclerosis }(28.12 \%), 41 \\
\text { of osteophytes ( } 25.62 \%) \text {, and } 66 \text { of erosion }(41.25 \%) \text { were } \\
\text { detected. Sclerosis had the most significant association with } \\
\text { pain, while sclerosis, osteophytes, and erosion were } \\
\text { significantly correlated with joint crepitation. }\end{array}$ \\
\hline
\end{tabular}

Abbreviations: CBCT, cone beam computed tomography; MRI, magnetic resonance imaging; NC, no comparison; RA, rheumatoid arthritis; TMD, temporomandibular disorder; TMJ, temporomandibular joint.

specialist or even from the otolaryngologist. Clinical examination has to be accompanied by different imaging modalities to rule out the exact underlying cause of TMJ pain. ${ }^{22}$

Conventional 2D radiographs has a vital role in initial TMJ screening, but are not preferable for evaluating the soft tissues and show some amount of magnification or superimposition of anatomical structures. ${ }^{8}$ MRI is considered as the modality of choice to examine the inflammatory and soft tissue changes as it does not involve exposure to ionizing radiation. MRI images provide clear visualization of disc position, medial and lateral disc displacements, and intra-articular degenerative alterations, and they also show condition of surrounding musculature with high resolution..$^{8,9}$ The main limitation of MRI is its reduced ability to detect osseous abnormalities, for 
Table 3 Population intervention comparator outcomes model summarizes studies from literature to evaluate the diagnostic accuracy of MRI-cone beam CT registration for the diagnosis and management of soft tissue and osseous abnormalities of temporomandibular joint

\begin{tabular}{|l|l|l|l|l|}
\hline $\begin{array}{l}\text { Study } \\
\text { (Year) }\end{array}$ & Population & Intervention & $\begin{array}{l}\text { Comparison/ } \\
\text { Control }\end{array}$ & Outcome \\
\hline $\begin{array}{l}\text { Al-Saleh et al } \\
(2015)^{16}\end{array}$ & $\begin{array}{l}\text { 20 TMJ of } 10 \\
\text { patients }\end{array}$ & $\begin{array}{l}\text { To evaluate image } \\
\text { quality of two methods } \\
\text { of registering MRI and } \\
\text { CBCT images of the TMJ, } \\
\text { particularly regarding } \\
\text { TMJ articular disc-con- } \\
\text { dyle relationship and } \\
\text { osseous abnormality }\end{array}$ & $\begin{array}{l}\text { MRI images, } \\
\text { CBCT images, and } \\
\text { MR-CBCT fused } \\
\text { images (Mirada } \\
\text { Software XD) }\end{array}$ & $\begin{array}{l}\text { 75\% of the nonguided registered images showed } \\
\text { excellent quality, and 95\% of the marker-guided } \\
\text { registered images showed poor quality. } \\
\text { MRI-CBCT fused images were slightly more } \\
\text { limited than CBCT alone to detect osseous } \\
\text { abnormalities, but improved detection of disc } \\
\text { position in relation to the condyle. }\end{array}$ \\
\hline $\begin{array}{l}\text { Ma et al } \\
(2019)^{21}\end{array}$ & Five case studies & $\begin{array}{l}\text { Fused images in detec- } \\
\text { tion of TMJ abnormalities }\end{array}$ & $\begin{array}{l}\text { MRI/CBCT reg- } \\
\text { istration (Amira } \\
\text { Visual software) }\end{array}$ & $\begin{array}{l}\text { Relationship between soft and hard tissue was } \\
\text { clearly seen in the fused images, these could } \\
\text { define the tumor outline and the destructive } \\
\text { bone clearly in the same image. }\end{array}$ \\
\hline
\end{tabular}

Abbreviations: CBCT, cone beam computed tomography; MRI, magnetic resonance imaging; NC, no comparison; TMJ, temporomandibular joint.

which confirmation by $\mathrm{CT}$ or $\mathrm{CBCT}$ examinations is required. ${ }^{13}$ Alkhader et al in his study found low sensitivity of MRI (30$82 \%$ in the detection of TMJ bony changes. Recently, CBCT is widely used in dentistry due to low radiation dose than $\mathrm{CT}$, and it provides details of osseous components of TMJ in all the three sagittal, coronal, and axial planes. ${ }^{8}$

Osteoarthritis $(\mathrm{OA})$ is a degenerative joint disease characterized by progressive degenerative changes in articulating surfaces of the TMJ, and is more frequently seen in patients above 40 years of age. It is associated with pain; restriction in joint function, joint noises, and involve degenerative bony changes that require accurate diagnosis by CBCT. By our search, seven studies demonstrated high diagnostic accuracy of $\mathrm{CBCT}$ in detection of condylar bony changes such as erosions, osteophytes, subchondral cysts, and flattening of articular surface. Higher prevalence of flattening (82.5$89.3 \%$ ), erosions (29.3-85.7\%), and sclerosis (30.2-64.3\%) were observed in the TMD patients as compared with controls. Another advantage of CBCT is that it enables clinician to obtain precise measurements of TMJ joint space, volume, and surface of condyle which significantly influence the treatment of TMD patients..$^{14,18}$ Calcifications of articular disc has been reported by few researchers, Al-Ekrish et al detected soft tissue calcifications of TMJ in $34 \%$ of cases. They have suggested that large FOV and voxel size can adversely affect the ability of CBCT to detect such small soft tissue calcifications, especially when clinical symptoms are nonspecific, it may lead to delayed or misdiagnosis. The low reliability of CBCT scanners with large FOV requires development of new CBCT protocols for accurate depiction of TMJ calcifications. ${ }^{15}$

Literature has well-revealed high diagnostic performance of CBCT for the diagnosis of TMJ osseous abnormalities, but its use for diagnosing soft tissue changes is still a controversial issue. To overcome this, merging of two CBCT images or MRI-CBCT fused images has evolved as a new concept that allows better interpretation of TMJ anatomical structures, masticatory muscles, and associated abnormalities. Two studies by our search concluded that fused images display relationship between hard and soft tissues, that is, disc condyle position more clearly than CBCT alone. ${ }^{19,21} \mathrm{Al}$-Saleh et al were first to introduce this registration concept in their research in which three observers independently evaluated three types of images, CT, MRI, and registered MRI-CBCT and found lower interobserver agreement for disc position by MRI than MRI-CBCT registered images. Poor to fair interobserver agreement was observed for MRI images in depiction of osseous pathologies affecting TMJ in comparison to MRI-CBCT images and CBCT images. Masking of small osseous changes like erosion by MRI images may be responsible for low diagnostic accuracy that emphasizes the need of more research work to establish the reliability of multimodal registration fusion imaging in dentistry. ${ }^{19}$

It is established that CBCT is recently expanding horizons of conventional CT due to its potential advantages. High submillimeter spatial resolution ranging from 0.25 to $0.4 \mathrm{~mm}$, rapid scan time of 10 to 70 seconds, and low effective patient dose reported to be $98 \%$ reduced in comparison to $\mathrm{CT}$. Researchers have found that few early CBCT machines with large FOV expose the patients to higher radiation dose, although comparatively less than conventional CT. These scanners have been optimized by use of small FOV, voxel size, pulsed radiation exposure, collimation, alteration of angle of rotation, etc. In addition, exposure of each individual should be clinically justified based on ALADA and patients should be recommended for $\mathrm{CBCT}$ imaging if the present clinical condition could not be diagnosed by conventional 2D radiography and requires further $\mathrm{CBCT}$ examination to arrive at accurate diagnosis and for effective treatment outcome. Thus, it is recommended to follow optimization and radiation dose should be kept ALARA. ${ }^{11,12}$

\section{Conclusion}

CBCT provides 3D information about facial skeleton and teeth and recently has become modality of choice for the evaluation of osseous structures of TMJ. But just as every good thing has limitations, so does CBCT technology. Dose levels of CBCT scanners with large FOV by far remained below those of clinical MDCT protocols, but higher than conventional 2D radiography. Moreover, it has limited use in detection of soft 
tissue abnormalities of TMJ and in demonstration of articular disc-condyle relationship. To overcome these limitations, new methods of dose reduction by CBCT optimization has considerably reduced the total effective dose and introduction of MRI-CBCT registration has made possible clear visualization of both hard and soft tissue TMJ components in one image. It is recommended to conduct more studies in this domain on larger population to validate the diagnostic performance of MRI-CBCT registration in the detection of TMJ abnormalities.

\section{Funding}

None.

\section{Conflict of Interest}

None declared.

\section{References}

1 Scarfe WC, Farman AG. What is cone-beam CT and how does it work? Dent Clin North Am 2008;52(4):707-730

2 Nair VV, Nair BJ. Cone beam computed tomography: hype and facts. J Indian Academy Oral Med and Radiol 2014;26:162-166

3 Zoller JE, Neugebauer J, Cone-Beam Volumetric Imaging in Dental, Oral and Maxillofacial Medicine: Fundamentals, Diagnostics, and Treatment Planning. Chicago: Quintessence Publishing;2008

4 De Vos W, Casselman J, Swennen GR. Cone-beam computerized tomography (CBCT) imaging of the oral and maxillofacial region: a systematic review of the literature. Int J Oral Maxillofac Surg 2009;38(6):609-625

5 Feldkamp LA, Davis LC, Kress JW. Practical conebeam algorithm. J Opt Soc Am 1994;1:612-619

6 Scarfe WC, Farman AG, Sukovic P. Clinical applications of cone-beam computed tomography in dental practice. J Can Dent Assoc 2006;72(1):75-80

7 Ferreira LA, Grossmann E, Januzzi E. de Paula MV, Carvalho AC. Diagnosis of temporomandibular joint disorders: indication of imaging exams. Rev Bras Otorrinolaringol (Engl Ed) 2016;82(3):341-352

8 Alkhader M, Kuribayashi A, Ohbayashi N, Nakamura S, Kurabayashi T. Usefulness of cone beam computed tomography in temporomandibular joints with soft tissue pathology. Dentomaxillofac Radiol 2010;39(6):343-348

9 Campos MI, Campos PS, Cangussu MC, Guimarães RC, Line SR. Analysis of magnetic resonance imaging characteristics and pain in temporomandibular joints with and without degenerative changes of the condyle. Int J Oral Maxillofac Surg 2008;37(6):529-534
10 Miracle AC, Mukherji SK. Conebeam CT of the head and neck, part 1: physical principles. Am J Neuroradiol 2009;30(6):1088-1095

11 Tsiklakis K, Donta C, Gavala S, Karayianni K, Kamenopoulou V, Hourdakis CJ. Dose reduction in maxillofacial imaging using low dose cone beam CT. Eur J Radiol 2005;56(3):413-417

12 Pauwels R, Jacobs R, Bosmans H, Schulze R. Future prospects for dental cone beam computed tomography. Imaging Med 2012;5:551-563

13 Nah KS. Condylar bony changes in patients with temporomandibular disorders: a CBCT study. Imaging Sci Dent 2012;42(4):249-253

14 Wang ZH, Jiang L, Zhao YP, Ma XC. [Investigation on radiographic signs of osteoarthrosis in temporomandibular joint with cone beam computed tomography in adolescents]. Beijing Da Xue Xue Bao 2013;45(2):280-285

15 Al-Ekrish AA. A retrospective study of the prevalence and reliability of the diagnosis of soft tissue calcification of the temporomandibular joint in cone beam computed tomography images. King Saud Univ J Dent Sci 2013;4:81-85

16 Al-Saleh MAQ, Jaremko JL, Alsufyani N, Jibri Z, Lai H, Major PW. Assessing the reliability of MRI-CBCT image registration to visualize temporomandibular joints. Dentomaxillofac Radiol 2015;44(6):20140244

17 Rehan OM, Saleh HAK, Raffat HA, Abu-Taleb NS. Osseous changes in the temporomandibular joint in rheumatoid arthritis: a cone-beam computed tomography study. Imaging Sci Dent 2018;48(1):1-9

18 Yasa Y, Akgül HM. Comparative cone-beam computed tomography evaluation of the osseous morphology of the temporomandibular joint in temporomandibular dysfunction patients and asymptomatic individuals. Oral Radiol 2018;34(1):31-39

19 Zhou Y, LiJP,LvWC, Ma RH, Li G. Three-dimensional CBCT images registration method for TMJ based on reconstructed condyle and skull base. Dentomaxillofac Radiol 2018;47(5):20170421

20 Maleki MH, Shokri A, Zarch SHH, Bahraniy A, Ebrahimpour A, Alimohamadi SM. Cone beam CT evaluation of the bony changes in the temporomandibular joint and the association with the clinical symptoms of temporomandibular joint disorders. J Dent Mater Tech 2019;8:25-32

21 Ma RH, Li G, Sun Y, Meng JH, Zhao YP, Zhang H. Application of fused image in detecting abnormalities of temporomandibular joint. Dentomaxillofac Radiol 2019;48(3):20180129

22 Wiese M, Svensson P, Bakke M, et al. Association between temporomandibular joint symptoms, signs, and clinical diagnosis using the RDC/TMD and radiographic findings in temporomandibular joint tomograms. J Orofac Pain 2008;22(3):239-251 